\title{
THERMAL ALTERATION OF INCLUSIONS IN "RUTILATED" TOPAZ
}

\author{
By Robert C. Kammerling and John I. Koivula
}

Faceted colorless topaz containing acicular inclusions has been offered for sale as "rutilated" topaz. Earlier investigations have shown the inclusions to be limonite-stained etched dislocation channels. This article reports on the use of heat treatment to alter the limonite staining to hematite, thus changing the color of the inclusions and making them more prominent.

The heat-induced alteration of iron-based impurities in gem materials is well documented in the literature. Such changes are often the goal of the gemstone enhancer, as in the heat treatment of colorless and light yellow sapphire to develop or intensify a yellow color (Abraham, 1982; Keller, 19821, the heating of light yellow to brown chalcedony to produce deep brown to red sard and carnelian colors (Nassau, 1984), and the heating of brownish yellow tiger's-eye quartz to produce a red stone (Webster, 1983).

Thermal exposure may also affect iron-based inclusions, a fact that is often used to detect treatment in a stone. For example, the conversion of goethite to hematite, together with associated dehydration fracturing, has been used as evidence of amethyst-to-citrine heat treatment (Koivula, 1987a).

During 1986, faceted Brazilian topazes containing brownish yellow acicular inclusions began to appear on the market. Because of the material's resemblance to rutilated quartz, dealers were describing these stones as "rutilated" topaz. Subsequent investigation by one of the authors revealed the "rutile" inclusions to be thin, etched dislocation channels colored by what appeared to be epigenetically derived (i.e., incorporated into the stone after formation) limonitic compounds (Koivula, 1987b).

In the fall of 1988 , one of the authors (RCK) was shown some interesting faceted Brazilian topazes at a Santa Monica gem and mineral show. These stones had eye-visible inclusions similar to those

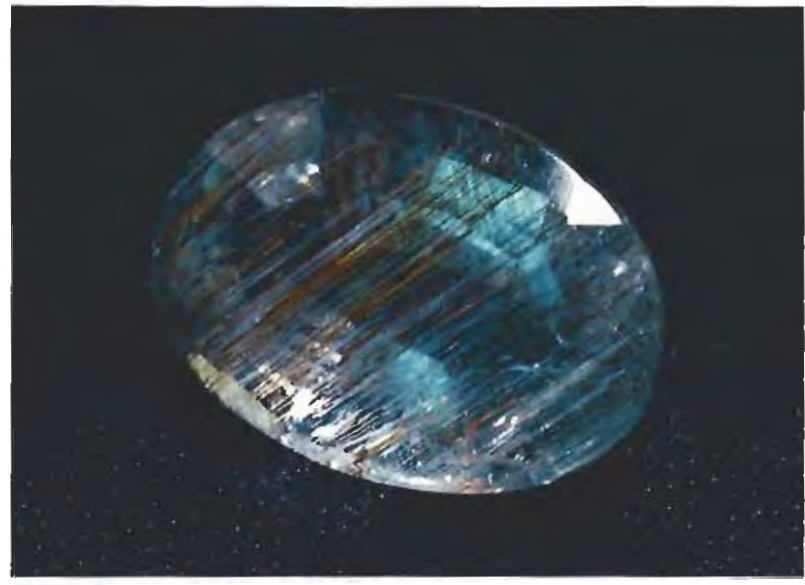

Figure 1. This 11.77-ct colorless topaz was reportedly heat treated to alter the inclusions. Photo by William Videto.

described earlier (Koivula, 1987b), but with one significant difference: They were a dark red-brown rather than a medium brownish yellow (figure 1). The vendor, Mr. Terry Johnson of The Gemmary, explained that he had heat treated these stones to make the inclusions more prominent. Specifically, Mr. Johnson said that he had heated the stones in air at a temperature of approximately $300^{\circ} \mathrm{C}$ and had experienced virtually no fracturing problems. Since there were no prior reports in the literature of such an enhancement of this material, the authors decided to attempt to replicate the procedure.

\section{ABOUT THE AUTHORS}

Mr. Kammerling is general manager of the Technical Development Department, and Mr. Koivula is chief gemologist, at the Gemological institure of America, Santa Monica, California.

Acknowledgments: The authors thank Mr. Terry Johnson of The Gemmary for bringing this material to their altention.

Gems \& Gemology, Vol. 25, №. 3, pp. 165-167

(C) 1989 Gemological Institute of America 

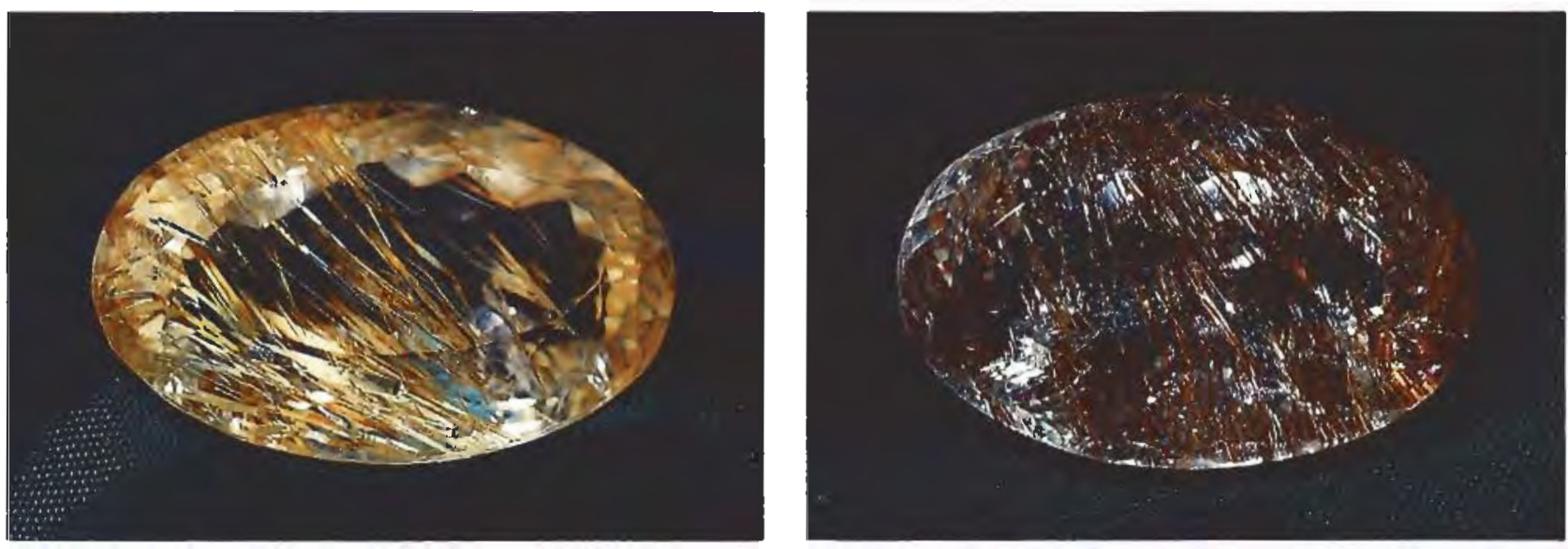

Figure 2. Before treatment, the inclusions (actually stained etch channels) in this otherwise colorless topaz were brownish yellow (left); exposure to $300^{\circ} \mathrm{C}-400^{\circ} \mathrm{C}$ heat for three hours resulted in the alteration of the inclusions to a dark red-brown (right). GIA collection no. 14490; photos by William Videto.

\section{THE EXPERIMENT}

For the experiment, the authors selected a 40.410ct colorless topaz (GIA collection no. 14490) containing limonite-stained etched dislocation channels (figures 2 left and 3 left). The weight was confirmed by six separate weighings on an electronic balance. The stone was then buried in white sand (to protect it from thermal shock) in an alumina crucible and heated in air for a period of three hours. The maximum temperature reached was $400^{\circ} \mathrm{C}$, with a variation between $300^{\circ}$ and $400^{\circ}$. The temperature was allowed to decrease slowly for three hours before the stone was removed from the oven.

The color alteration of the inclusions was quite apparent (see figures 2 right and 3 right). In addition, when the stone was reweighed, all six readings showed $40.406 \mathrm{ct}$, for a weight loss of $0.004 \mathrm{ct}$.

\section{DISCUSSION}

Limonite is a general term for hydrous cryptocrystalline iron oxides consisting mainly of goethite $[\alpha-\mathrm{FeO}(\mathrm{OH})]$ and lepidocrocite $[\gamma-$

Figure 3. The effectiveness of the heat treatment is particularly evident in these photomicrographs of the stained etch channels in colorless topaz before (left) and after (right) the enhancement procedure. Photomicrographs by John I. Koivula; darkfield and oblique fiber-optic illumination, magnified $20 \times$.
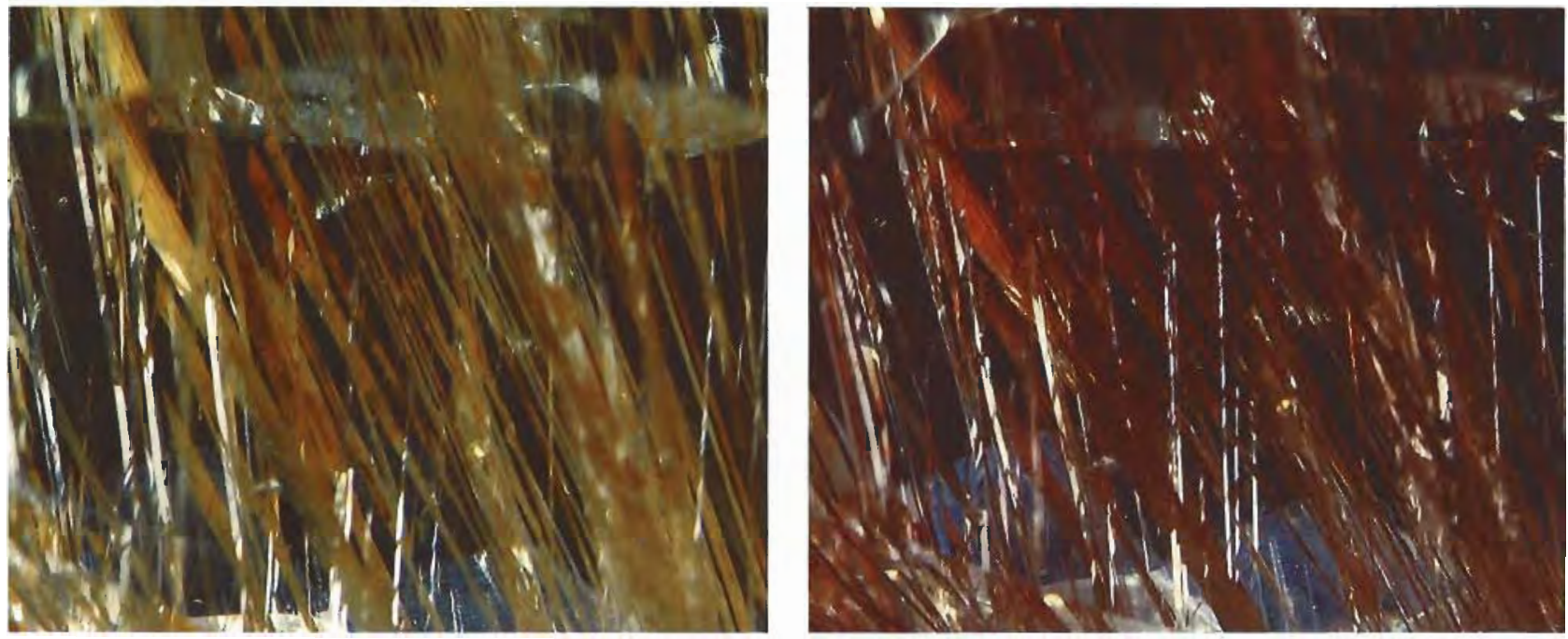
$\mathrm{FeO}(\mathrm{OH})]$ with variable absorbed water. Heating of the earthy yellow limonite causes a gradual dehydration (Palache et al., 1944) that starts at $100^{\circ} \mathrm{C}$ with the loss of excess water from the limonite. It continues with the conversion of the goethite and lepidocrocite in the limonite to dark red-brown hematite $\left(\alpha-\mathrm{Fe}_{2} \mathrm{O}_{3}\right)$, following the formula $2 \mathrm{FeO}(\mathrm{OH})+$ heat $\left(400^{\circ} \mathrm{C}\right) \rightarrow \mathrm{Fe}_{2} \mathrm{O}_{3}+\mathrm{H}_{2} \mathrm{O}$, with a resulting additional loss of water (Koivula, 1987a). Because the limonite may contain as much as 14\% water (Deer et al., 1972) and there are a large number of limonite-filled etch channels in the test specimen, a recordable weight loss is not surprising. Although the inclusions in the topaz treated in this experiment showed the expected alteration in color, none of the fracturing that normally accompanies heat-induced dehydration of inclusions was observed (Koivula, 1987a). We believe that fracturing was avoided because the etch channels acted as vents, allowing the water and resulting pressure to escape.

There are no reports in the literature of hematite filling etched channels in topaz. It appears, then, that the presence of hematite in these channels is also evidence that the stone has been heated.

\section{CONCLUSION}

The purpose of the treatment described herein appears to have been simply to alter the appearance of so-called "rutilated" topaz as normally seen in the trade. The conversion of the untreated brownish yellow limonite to red-brown hematite does tend to make the otherwise colorless topazes treated this way look much darker. This conversion provides further proof that the original inclusions were not rutile. The presence of hematite as opposed to limonite staining in a topaz also proves that the stone has been heated to approximately $400^{\circ} \mathrm{C}$ or higher.

\section{REFERENCES}

Abraham J. \{1982\} Heat treating corundum: The Bangkok operation. Gems aemology, Vol. 18, No. 2, pp. 79-82.

Deer W.A., Howie R.A., Zussman J. (1972) Rock-Forming Minerals, Vol, 5. Longman Group, London

Keller P.C. (1982) The Chanthaburi-Trat gem field, Thailand. Gems e) Gemology, Vol. 18, No. 4, pp. 186-196.

Koivula J.1. (1987a) Goethite inclusion alteration during the heat conversion of amethyst to citrine. Australian Gemmologist, Vol, 16, No. 7, pp. 271-272.

Koivula f.l. (1987b) The rutilated topaz misnomer. Gems e.) Gemology, Vol. 23, No. 2, pp. 100-103.

Nassau K. (1984) Gemstone Enhancement. Butterworth \& Co., London.

Palache C., Berman H., Frondel C. $\mathrm{C} 1944\}$ The System of Mineralogy, Vol. 1. John Wiley \& Sons, New York.

Webster R. (1983) Gems, 4th ed. Butterworth \& Co., London.

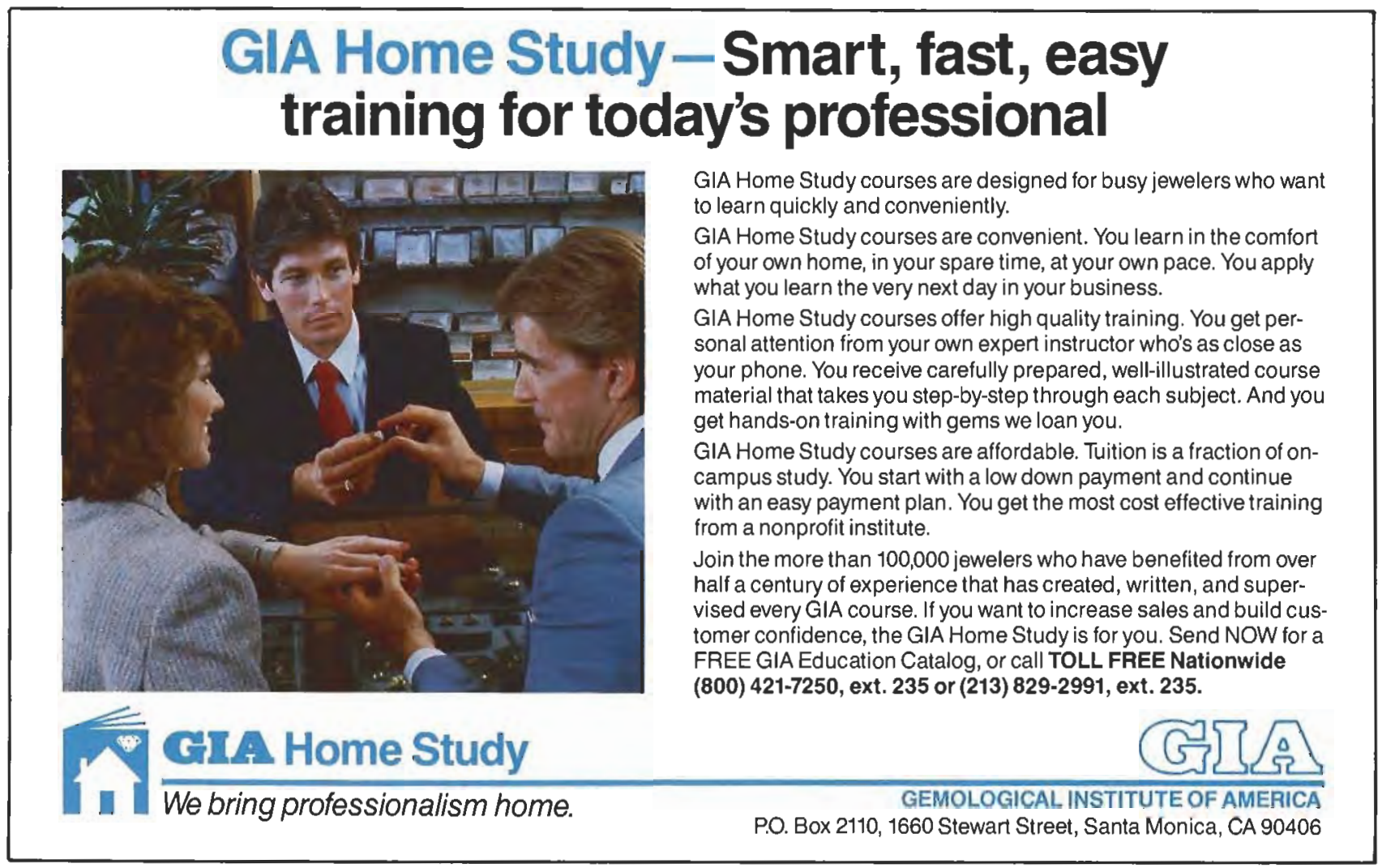

